\title{
YKL-40 Correlates with Soluble CD 40 Ligand in Old Myocardial Infarction with Hypertension
}

\author{
Diah Kumalasari ${ }^{1,2 *}$, Andi Wijaya ${ }^{1,3}$, Anwar Santoso $^{4}$
}

\begin{abstract}
'Post Graduate Program in Clinical Biochemistry, Hasanuddin University, Jl. Perintis Kemerdekaan Km. 10, Makassar, Indonesia ${ }^{2}$ Prodia Clinical Laboratory, Jl. Bintaran Kulon No. 28, Yogyakarta 55155, Indonesia ${ }^{3}$ Prodia Clinical Laboratory, Jl. Cisangkuy No. 2, Bandung, Indonesia ${ }^{4}$ National Cardiovascular Center, Harapan Kita Hospital, Jl. Let. Jend. S. Parman Kav. 87, Slipi, Jakarta, Indonesia *Correspondence: sari.kum2@yahoo.com
\end{abstract}

\section{Abstract}

ACKGROUND: Myocardial infarction is one of the coronary artery diseases caused by plaque rupture, plaque erosion or calcfified nodules, with the occurence of thrombus formation and artery occlusion. YKL-40 has a functional role in plaque fibrous formation because of its high expression during fibrosis development, vascular smooth muscle cells differentiation, elevated matrix turnover and tissue remodelling in old myocardial infarction, whereas CD40 ligand, which is stored in the cytoplasm of resting platelets, rapidly presents on the surface. After cleavage, a soluble functional CD40 ligand (sCD40L) is generated. The aim of this study was to assess the association between YKL-40 and sCD40L in old myocardial infarction.

METHODS: This study used the cross sectional study design. Fifty six patients with old myocardial infarction were selected based on their electrocardiographical results. Among these patients, 23 subjects had hypertension and 15 subjects had hsCRP $>3-10 \mathrm{mg} / \mathrm{L}$. YKL-40 and sCD40L were measured by ELISA method.

RESULTS: There was no significant correlation between YKL-40 and sCD40L ( $r=0.078 ; p=0.569)$ in old myocardial infarction and in subjects with hsCRP > 3-10 $\mathrm{mg} / \mathrm{L}(\mathrm{r}=0.524 ; \mathrm{p}=0.045)$. However, significant positive correlations were found in subjects with hypertension $(\mathrm{r}=$ 0.447; $\mathrm{p}=0.029$ ).
CONCLUSIONS: Our findings showed that YKL 40 correlated significantly with $\mathrm{SCD} 40 \mathrm{~L}$ in subjects with hypertension.

KEYWORDS: Myocardial infarction, ruptured plaque, coronary artery disease, YKL-40, soluble CD40 Ligand.

Indones Biomed J 2012; 4 (1): 29-34

\section{Introduction}

Coronary artery disease or cardiovascular disease currently has become the leading cause of death and illness in the developing countries and will soon become the pre-eminent health problem worldwide (1). Coronary artery disease comprises narrowing of the coronary arteries caused by atherosclerosis which can manifest as angina pectoris and myocardial infarction (2). Plaque rupture is the most common type of plaque complications, accounting for $70 \%$ of fatal cardiovascular events (3). Necrotic core lesion with a thin fibrous cap can rupture and leads to luminal thrombosis due to contact of platelets with a highly thrombogenic necrotic core. This is defined as ruptured plaque (4). The ruptured plaque has a large lipid core composed of foam cells, apoptotic and necrotic cells, debris, and is separated from the lumen by a fibrous cap (mainly comprising collagen, proteoglycans, and smooth muscle cells), which is actively weakened both by lytic process and a lack of repair; this results eventually in 
the plaque fissuring at the point, which ultimately brings the platelets into contact with the content of the lipid core, and the blood coagulation factors together with tissue factor (5).

YKL 40 (Human cartilage glycoprotein-39/HCgp 39 or $38-\mathrm{kDa}$ heparin-binding glicoprotein/gp38k) has a functional role in plaque fibrous formation. It is upregulated in the extracellular matrix of injured vessel wall and has been reported to be involved in smooth muscle cell proliferation. The presence of heparin binding activity YKL-40 suggests the possibility that it may bind with glycoprotein or proteoglycan component of the extracellular matrix or cell surface to modify cell adhesion, cell motility or gene expression and influence the phenotypic state of the smooth muscle cell during the process of recovery from injury (6). Hakala suggested that elevation of degradation extracellular matrix components in the rheumatoid joint expresses YKL-40 and may be associated with a response of cells to an altered tissue environment. The presence of TGF- $\beta$, which is the most potent stimulus of interstitial collagen smooth muscle cells synthesis, strongly decreases mRNA concentrations for YKL-40 (7). Ling suggested that elevated matrix turnover and tissue remodelling expressed YKL-40. In this study, YKL 40 had a physiological role in limiting the catabolic effects of inflammatory cytokines (8). The involvement of YKL 40 in the homoeostasis of connective-tissue cells caused by increased secretion of YKL-40 under physiological and pathological conditions is associated with elevation of connective-tissue turnover. A signalling cascade in connective-tissue cells initiated by YKL-40 can induce cell proliferation, suggesting that this protein could play a major role in pathological conditions leading to tissue fibrosis (9). Serum YKL-40 concentrations in patients with coronary artery disease were statistically significantly higher than in control participants. Concentration of YKL-40 has a significant correlation with the extent of coronary artery disease defined by the number of stenosed vessels (10). Serum concentration of YKL-40 is greatly elevated in patients with acute myocardial infarction (11)

Platelets play a key role in the development of acute coronary syndromes by participating in the process of forming and extending atherosclerotic plaques. Platelets activated by inflammatory triggers may be critical components of atherothrombosis. The activation of platelets releases inflammatory and mitogenic substances into the microenvironment, primarily altering the chemotactic, adhesive and proteolytic properties of the endothelium. CD40 ligand is stored in the cytoplasm of resting platelets and is rapidly released into the surface after platelet activation. After cleavage, to generate a soluble functional fragment (soluble CD40 ligand), the mediator is present to the extracellular environment, inducing inflammatory responses in the endothelium by interacting with CD40 on endothelial cells (12). Soluble CD40 ligand is a powerful biochemical marker of inflammatory thrombotic activity in patients with acute coronary syndromes. Increased concentration of soluble CD40 ligand reliably shows the subgroup of patients with acute coronary syndromes who has the highest risk for cardiac events (13)

The aim of this study was to assess the association between YKL-40, which has a functional role in plaque fibrous formation, and sCD40L, which is increased in activated platelet in patients with old myocardial infarction.

\section{Methods}

For selection of the study subjects with old myocardial infarction we used electrocardiographic results of patients, by which 45 men and 11 women were selected. All patients with cancer, asthma, alcohol intake, osteoarthritis (based on questionnaire), Alanin Aminotransferase (ALT) $>100 \mathrm{mg} / \mathrm{dL}$, high sensitivity-C Reactive Protein (hsCRP) $>10 \mathrm{mg} / \mathrm{L}$, and abnormal cell blood count (WBC $>16000 / \mathrm{uL}$ ) were excluded. Blood samples were taken after an overnight fasting for 12-14 hours. The collected samples were seated for 30-60 minutes, then the serum was separated from the cellular element by centrifugation $1000-1200 \mathrm{~g}$ for 10 minutes. All serum samples were stored at $-20^{\circ} \mathrm{C}$. Our study protocol was approved by the institusional review board of the Health Research Ethic Committee, Faculty of Medicine, Hasanuddin University, Makassar, Indonesia. All written informed consents were obtained from patients.

\section{ASSAY OF BIOCHEMICAL MARKERS}

Fasting plasma glucose (FPG), hsCRP, ALT, cell blood count, YKL-40, sCD40L were examined at Prodia Clinical Laboratory. FPG was determined using the hexokinase method (catalog 1447513) (19), reagents manufactured by Roche Diagnostic (Indianapolis, USA). ALT was measured using the IFCC method (catalog 0851132) (20), reagents manufactured by Roche Diagnostic. hsCRP (catalog LKCR1) was measured using sensitive 
immunoassay method, manufactured by Diagnostic Products Corporation (Los Angeles, USA). Cell Blood Count reagents manufactured by Abbot Diagnostic (USA). YKL-40 (Catalog 8020) was determined using ELISA method manufactured by Metra Quidel Corporation (San Diego, USA). sCD40L (catalog DCDL40) was measured using ELISA method manufactured by Quantikine R\&D system (Minneapolis, USA).

\section{STATISTICAL ANALYSIS}

Data analysis was carried out with the SPSS for Windows version 11.5 software. For Pearson statistical correlation tests we used 5\% significance concentration.

\section{Results}

The study subjects comprised 56 participants with old myocardial infarction based on their electrocardiographic recordings. Among these patients, 23 subjects were with hypertension and 15 subjects with hsCRP $>3-10 \mathrm{mg} / \mathrm{L}$. ALT and hsCRP, which reflect liver function and acute inflammation respectively, of the 56 study subjects were within normal limit. Table 1 shows the general description of the baseline characteristics of the study subjects.

Table 2 shows no significant correlation between YKL-40 and sCD40L in coronary artery disease with old myocardial infarction and in subjects with hsCRP > 3-10 mg/L ( $\mathrm{n}=15)$ (Figure 2). However, in subjects with hypertension $(n=24)$ (Figure 1), we found statistically significant correlation between YKL-40 and sCD40L.

Table 1. Baseline characteristics of the study subjects

\begin{tabular}{lcccrc}
\hline \multicolumn{1}{c}{ Variables } & N & Minimum & Maximum & Mean & \multicolumn{1}{c}{ SD } \\
\hline Age (Years) & 56 & 30.00 & 75.00 & 58.75 & 9.51 \\
Blood Pressure & & & & & \\
Systolic (mmHg) & 56 & 90.00 & 200.00 & 139.29 & 25.16 \\
Diastolic (mmHg) & 56 & 60.00 & 120.00 & 86.52 & 11.98 \\
FPG (mg/dL) & 56 & 75.00 & 443.00 & 113.57 & 63.20 \\
hsCRP $(\mathrm{mg} / \mathrm{L})$ & 56 & 0.20 & 10.00 & 2.28 & 2.35 \\
YKL-40 (ng/mL) & 56 & 16.36 & 361.12 & 133.09 & 94.11 \\
sCD40L (ng/mL) & 56 & 0.75 & 25.39 & 7.10 & 4.20 \\
\hline
\end{tabular}

FPG = Fasting Plasma Glucose; hsCRP = High-Sensitivity C-Reactive Protein; sCD40L = Soluble CD40 Ligand.

Table 2. Correlation between YKL-40 and SCD40L in Coronary Artery Disease with old myocardial infarction $(n=56)$

\begin{tabular}{ccc}
\hline Variable & & sCD40L \\
\hline YKL-40 & $r$ & 0,078 \\
& $p$ & 0.569
\end{tabular}

sCD40L $=$ Soluble CD40 Ligand $; r=$ pearson correlation coefficient $; p=$ significance. 


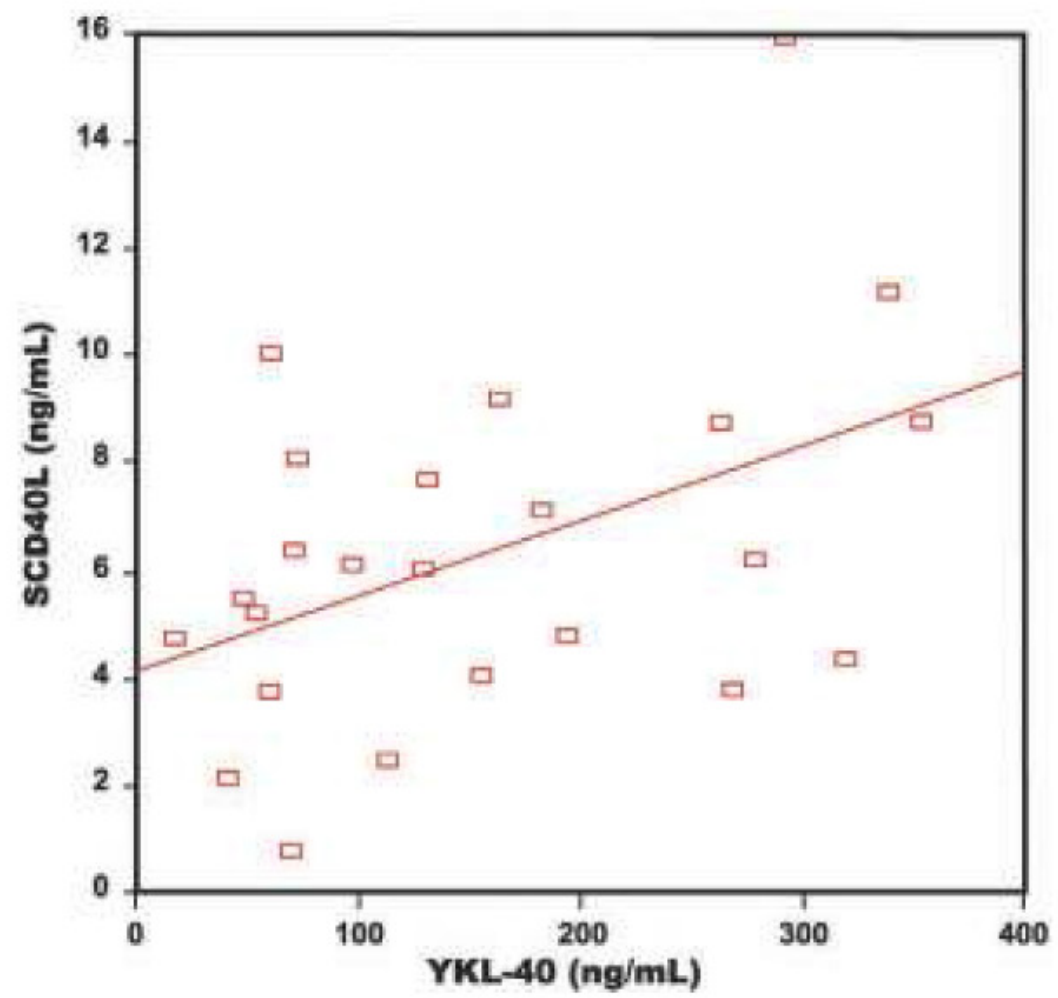

Rsq $=0.1997$

Figure 1. $\mathrm{sCD} 40 \mathrm{~L}$ according to $\mathrm{YKL}-40$ in subjects with hypertension $(\mathrm{N}=24)$ $r=$ pearson correlation coefficient $; p=$ significance $;\left(^{\star}\right)=$ Indicate significant $(p<0.05)$.

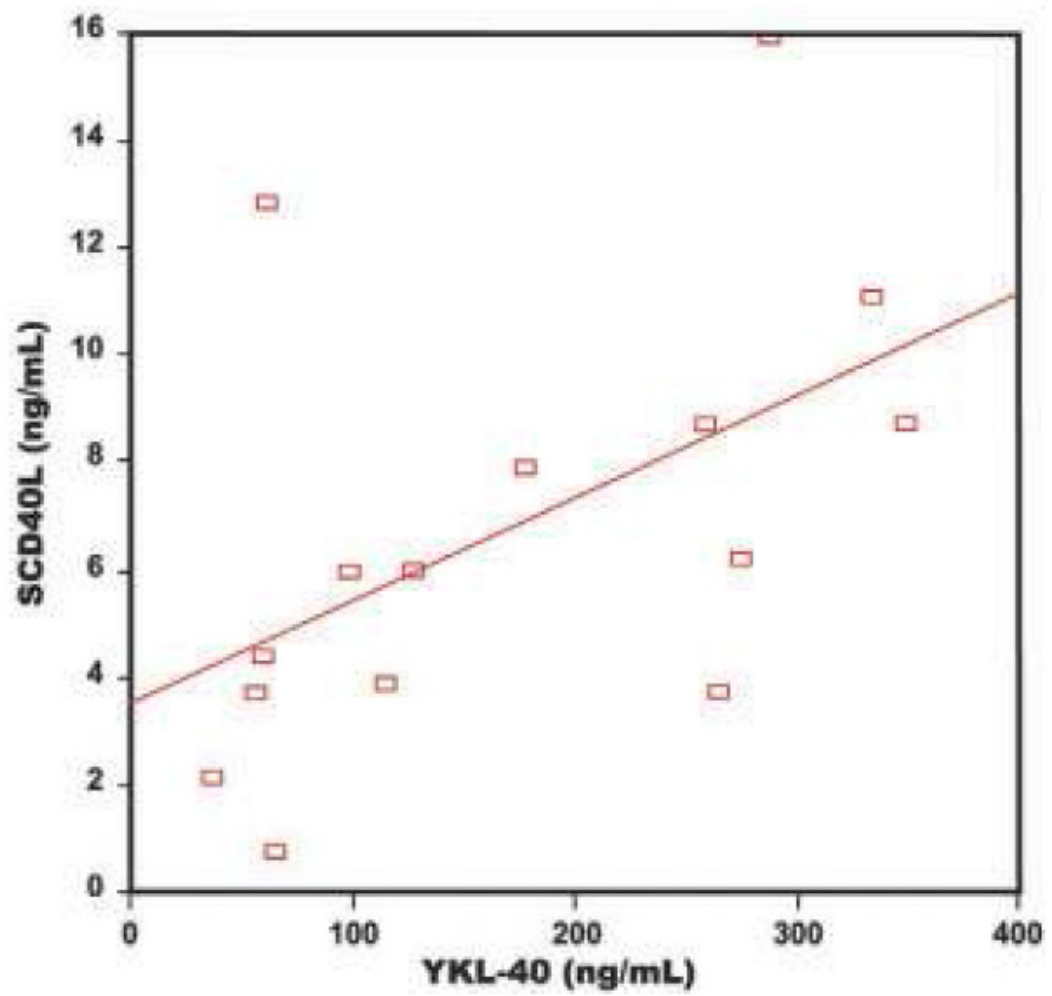

Rsq $=0.2742$

Figure 1. sCD40L according to YKL-40 in subjects with hsCRP $>3-10 \mathrm{mg} / \mathrm{L}$ $(N=15), r=$ pearson correlation coefficient ; $p=$ significance $;\left(^{*}\right)=$ Indicate significant $(p<0.05)$. 


\section{Discussion}

In this study, we found no statistically significant correlation between YKL-40 and SCD40L in coronary artery disease with old myocardial infarction and in subjects with hsCRP $>3-10 \mathrm{mg} / \mathrm{L}$. In subjects with hypertension we found a significant correlation. Although the mechanism is clear, expression of YKL-40 is related with conditions of elevated matrix turnover and tissue remodelling (8). Nojgaard showed that serum concentrations of YKL-40 were associated with liver fibrosis. The serum concentration of YKL- 40 was associated with the presence of fibrosis and might be used as a marker of fibrosis (14). The elevated serum YKL-40 in patients with liver disease of various degree and aetiology seems to reflect fibrosis and fibrogenesis (15). In vitro studies have shown that YKL-40 is a growth factor of fibroblasts and increased cell proliferation, suggesting that this protein could play a major role in the pathological conditions leading to tissue fibrosis (9). YKL-40 is a potent migration factor for endothelial cells (16).

The ruptured plaque consists of a large lipid core composed of foam cells, apoptotic and necrotic cells, debris, and is separated from the lumen by a fibrous cap (mainly comprising of collagen, proteoglycans, and smooth muscle cells), which is actively weakened both by lytic process and a lack of repair (5). "Vulnerable plaque" is most suitable to define plaque susceptible to complication, including rupture (3). When the plaque ruptures, blood becomes in contact with the tissue factor in the plaque coagulates. Platelets activated by thrombin generated from the coagulation cascade and by contact with the intimal compartment instigate thrombus formation (17). When platelets is activated by thrombin, CD40 ligand, which is stored in the cytoplasm of resting platelets, rapidly presents on the surface. After cleavage, to generate a soluble, functional fragment (soluble CD40 ligand), the mediator is released into the extracellular environment, inducing inflammatory responses in the endothelium by binding CD40 on endothelial cells (12). If the thrombus occludes the vessel persistently, an acute myocardial infarction occurs (14).

YKL-40 has a functional role in plaque fibrous formation (9) which causes the plaque to rupture. Ruptureprone plaques are not the only vulnerable plaques. All types of atherosclerotic plaques with high likelihood of thrombotic complications and rapid progression should be considered as vulnerable plaques (3). The most common cause of coronary thrombosis is plaque rupture followed by plaque erosion, whereas calcified nodule is rare. The term vulnerable plaque should be reserved for plaque that resemble all three causes of luminal thrombosis, and these morphologies include thin cap fibroatheroma, pathological intimal thickening, thick cap fibroatheroma and calcified plaque with luminal calcified nodules (4). The rate of plaque rupture varies from $60-70 \%$. The occurrence of plaque erosion in necropsy studies of patient after sudden coronary death was $25-44 \%$. Plaque calcification is a plaque associated with coronary thrombosis in the absence of ruptured or eroded plaque, although more infrequent (5\%) (5). No significant correlation between YKL-40 and sCD40L in this research may be explained that not all of the myocardial infarction in this study population is caused of plaque rupture. Another reason is vulnerable plaques are not the only factors for the development of acute coronary syndromes, myocardial infarction, and sudden cardiac death. Vulnerable blood causes thrombosis, and vulnerable myocardium causes fatal arrhythmia, which play an important role in the clinical manifestation of cardiovascular disease. Risk assessment of vulnerable patients needs to be developed that may include variables based on plaque, blood, and myocardial vulnerability (18).

\section{Conclusions}

YKL-40 has no significant correlation with sCD40L in coronary artery disease with old myocardial infarction. YKL-40 has a statistically significant correlation with sCD40L in subjects with hypertension.

\section{Acknowledgement:}

We thank the Prodia Education and Research Institute for the invaluable support given to this study.

\section{References:}

1. Murray CJ, Lopez AD. Global mortality, disability, and the contribution of risk factors: Global Burden of Disease Study. Lancet 1997; 349: 1436-42.

2. Majid, A. Coronary Heart Disease: Pathophysiology, Prevention and Current Treatment. Inauguration Speech Professor of Fixed Position in the Field of Science Physiology at the Faculty of Medicine, said in front of the Open Meeting of North Sumatra University, USU Campus Student Center, Medan, August 4, 2007.

3. Naghavi M, Libby P, Falk E, Casscells W, Litovsky S, Rumberger $\mathrm{J}$, et al. From Vulnerable Plaque to Vulnerable Patient - a Call for New Definitions and Risk Assessment Strategies: Part I. Circulation. 2003; 108: 1664-72. 
4. Virmani R, Burke AP, Farb A, Kolodgie FD. Pathology of the Vulnerable Plaque. J. Am. Coll. Cardiol 2006; 47: C13-8.

5. Lafont, A. Basic Aspects of Plaque Vulnerability. Heart $2003 ; 89$ : 1262-67.

6. Shackelton LM, Mann DM and Millis AJ. Identification of a 38$\mathrm{kDa}$ Heparin-Binding Glycoprotein (gp38k) in Differentiating Vascular Smooth Muscle Cells as a Member of a Group of Proteins Associated with Tissue Remodeling. J. Biol. Chem 1995; 270: 13076-83.

7. Hakala BE, White C, Recklies AD. Human Cartilage gp-39, a Major Secretary Product of Articular Chondrocytes and Synovial Cells, Is a Mammalian Member of Chitinase Protein Family. Biochem J 1993; 268: 25803-10.

8. Ling $H$, Recklies AD. The Chitinase 3-Like Protein Human Cartilage Glycoprotein 39 Inhibits Cellular Responses to the Inflammatory Cytokines Interleukin-1 and Tumour Necrosis Factor-a. Biochem. J 2004; 380: 651-9.

9. Recklies $A D$, White $C$, Ling $H$. The Chitinase 3-Like Protein Human Cartilage Glycoprotein 39 (HC-gp39) Stimulates Proliferation of Human Connective-Tissue Sells and Activates both Extracellular Signal-Regulated Kinase- and Protein Kinase B-Mediated Signalling Pathways. Biochem J 2002; 365: 119-26.

10. Kucur M, Isman KF, Karadag B, Vural VA, Tavsanoglu S. Serum YKL-40 Concentrations in Patient with Coronary Artery Disease. Coronary Artery Disease 2007; 18: 391-6.

11. Nojgaard C, Host NB, Christensen J, Poulsen SH, Egstrup K, Price PA, et al. Serum Concentrations of YKL-40 Increases in Patients with Acute Myocardial Infarction. Coronary Artery Disease 2008; 19(4): 257-63.

12. Davi G, Patrono C. Platelet Activation and Aterothrombosis. N Engl J Med 2007; 357: 2482-94.

13. Heeschen C, Dimmeler S, Hamm CW, Brand MJ, Boersma E, Zeiher AM, et al. Soluble CD40 Ligand in Acute Coronary Syndromes. N Engl J Med 2003; 348: 1104-11.

14. Nojgaard C, Johansen JS, Christensen E, Skovgaard LT, Price PA, Becker U. Serum Concentrations of YKL-40 and PIIINP as Prognostic Markers in Patients with Alcoholic Liver Disease. J Hepatol 2003; 39: 179-86.

15. Johansen JS, Christoffersen P, Moller S, Price PA, Henriksen JH, Garbarsch C, et al. Serum YKL-40 is Increased in Patients with Hepatic Fibrosis. J Hepatol 2000 ; 32: 911-20.

16. Malinda KM, Ponce L, Kleinman HK, Shackelton LM, Millis AJT. Gp38k, a protein synthesized by vascular smooth muscle cells stimulates directional migration of human umbilical vein endothelial cells. Exp Cell Res 1999; 250: 168-73.

17. Libby P. Inflammation in Atherosclerosis. Nature 2002; 420: 86874.

18. Naghavi M, Libby P, Falk E, Casscells W, Litovsky S, Rumberger $\mathrm{J}$, et al. From Vulnerable Plaque to Vulnerable Patient - a Call for New Definitions and Risk Assessment Strategies: Part II. Circulation 2003; 108:1672-78.

19. Kit Insert Glucose (Glucse/HK). Roche - Hitachi (2008-09, V7 English).

20. Kit Insert ALT (ALAT/GPT). Roche (2007-12, V10 English). 